\title{
Public Finance Policy and Technological Innovation in China
}

\author{
Yaling $\mathrm{Li}^{1}$, Yuting $\mathrm{Li}^{1}$, Rui Liu ${ }^{1}$ \\ ${ }^{1}$ School of Business and Tourism Management, Yunnan University, Chenggong District, Kunming, Yunnan, China, 650500
}

\begin{abstract}
Technological innovation is the core power to promote economic growth, and public financial policy plays an important role in stimulating enterprises to carry out technological innovation. The new technological revolution has not only provided opportunities but also posed serious challenges to developing countries. We must adapt to the development trend of the new technological revolution, change the traditional model of economic development, formulate new development strategies, improve existing public policies, constantly raise the level of science and technology, and embark on the road of making China a technologybased country. By analyzing the relationship between technological innovation and public financial policy, this paper draws out the shortcomings of China's existing fiscal policy in promoting technological innovation, and makes a comparative analysis of the fiscal policy of the United States and draws on its experience, so as to get the technical innovation suggestions under China's public financial policy.
\end{abstract}

\section{Introduction}

Technological innovation refers to a comprehensive process in which entrepreneurs seize the potential profit opportunities in the market, reorganize production conditions and elements for the purpose of obtaining economic benefits, and constantly launch new products, new processes and new technologies to gain market recognition. From the macroscopic point of view, the understanding of the effect of technological innovation on national economic development deepens with the development of economic growth theory.

From the evolution and development process of economic growth theory, the traditional economic development theory believes that the focus of developing countries' economic development is savings and material capital accumulation. However, with the combination of the reality and the continuous exploration and research of the factors affecting economic growth, the role of technology has been increasingly seen and paid attention to. Nowadays, the decisive factors of economic development are no longer capital, cheap labor, natural resources, etc., but knowledge, technology, information, patents, etc. The new technological revolution has created opportunities as well as challenges for developing countries.

At present, China has entered the economic "new normal", in which economic growth has shifted from a stage of high-speed growth to a stage of high-quality development, and the economic development mode has also shifted from a scale and speed type of extensive growth to a quality and efficiency type of intensive growth. Technology-intensive enterprises have become the mainstream in the future, and innovation-driven enterprises have become the core of China's economic development. Since technological innovation has the characteristics of publicity, spillover, high risk and uncertainty, it is of great significance for the government to intervene and promote enterprise technological innovation through public financial policy.

Arrow and K.J (1962) believed that enterprise technological innovation was high-risk and inseparable, and the profits brought by it were not exclusive. Therefore, it was unrealistic to rely only on market forces to achieve the optimal allocation, and the government needed to intervene, of which public financial policy was an important part. Because of the positive externality of technological innovation, we must rely on the policy intervention of taxation, science and technology allocation, financial preference, financial subsidy, public expenditure and so on to maintain the market order and realize the organic unity of property rights and regulation content. In the short run, expanding government fiscal expenditure and stimulating domestic demand can effectively promote economic growth, but in the long run, technological innovation is the most sustainable and important driving force of economic growth. Under the public finance system, in order to meet the public needs, the government provides some public products such as public security, public order, public education and public facilities in order to make up for the lack of market, so as to cope with public risks. With the advancement of economic system reform, government functions have been gradually transformed, and the government has gradually realized that technological innovation and technology diffusion play a decisive role in productivity and competitive advantage. Therefore, the use of public financial policy to support technological innovation has become an important part of the government's science and technology policy, which is also the most important and the most effective part of the government in supporting technological innovation. 
It is determined by the nature of public goods of technological innovation that the government promotes technological innovation and technological diffusion by investing public financial resources. On the one hand, technological innovation is public and spillover. Technological innovation can be regarded as the generation of new knowledge or the reorganization of the acquired knowledge. Therefore, whether the technological innovation results appear in the form of new products, new processes or new organizations, they all contain new knowledge, and the use of new knowledge by others will promote the increase of new knowledge and induce the emergence of new technological innovation. From this point of view, technological innovation is public, and its benefits are mainly social benefits, which are far greater than personal benefits. In this case, market failure is likely to occur if no corresponding compensation is obtained. Due to the public nature of technological innovation, spillover effect of technological innovation will be generated if the technological achievements obtained from a large amount of resources invested by an enterprise can be obtained by other enterprises at low or no cost. When personal income cannot make up for the innovation cost, enterprises' enthusiasm for technological innovation research and development will be weakened, which will lead to technological innovation stagnation and the decrease of marginal revenue of innovative enterprises. Therefore, it is necessary for the government to stimulate the technological innovation of enterprises through public financial policy intervention, so as to realize the optimal allocation of resources and make the supply reach the optimal level of society.

On the other hand, technological innovation has uncertainty and high risk. Technology is a complex and long process from research and development to application. In the process of research and development, there are often many uncertain factors, and the innovation results are also of great uncertainty. In addition, the inputoutput relationship of technological innovation is uncertain. It is not clear how much resources should be invested, how much output can be obtained, and how much economic value can be generated. The uncertainty of technological innovation leads to huge risks in the process of innovation. Because the relationship between input and output is determined by the form of random probability, technological innovation has high risk. In order to eliminate the uncertainty and high risk of technological innovation, the government should support innovative enterprises through financial policies and establish the system environment suitable for technological innovation.

Overall, from an economic perspective, for enterprise technological innovation is a kind of high risk spillover, technology innovation resources required to invest more and long time consuming and can not fully conform to the enterprise's desired outcome. If the interest obtained in the process of technological innovation is lower than the average level, it will cause the phenomenon of insufficient motivation and innovation output lower than the social demand, and then make the market failure. Therefore, that the government adopts fiscal policy to intervene can make up for the market shortage and effectively promote the development of technological innovation.

\section{FISCAL policies to encourage technological innovation:Theoretical framework}

\subsection{Fiscal Expenditure Policy}

Government fiscal policy can promote the capital turnover of enterprises' technological innovation, including science and technology allocation, financial subsidies, etc., which is a kind of direct capital input from the government to enterprises' technological innovation, and can promote the research and development activities of technological innovation. It is a common practice to promote technological innovation through funding for science and technology, which supports technological innovation. Especially for small and medium-sized enterprises, this kind of direct capital investment greatly promotes its technological innovation and research.

Generally speaking, China's financial allocation is mainly used for scientific undertakings, national key basic special funds and special funds for technology development and research in scientific research institutions. In addition, it also focuses on supporting some special programs, such as special funds for high and new technology research. Science and technology investment policies mainly play a role in the R\&D stage of technological innovation. The government can directly invest in enterprises or set up various government innovation and development funds to make indirect investment in enterprises. The role of fiscal subsidies is more extensive, and different types of subsidies are applicable to different stages of the technological innovation R\&D process. No matter which kind of policy is adopted, it can promote the government's support for innovative enterprises, increase the capital source of innovative enterprises, reduce their innovation risks, and keep the technological innovation going continuously.

\subsection{Fiscal Guarantee}

Information asymmetry exists between enterprises and financial institutions. For example, when financial institutions such as banks provide loans to enterprises in the review process, banks will require enterprises to fill in some information of technological innovation. However, in the process of technological innovation and development, enterprises involve many trade secrets that cannot be disclosed to the public, which will lead to the game between enterprises and financial institutions. This will limit the source and amount of corporate research funding. However, only the capital turnover of the enterprise and a certain amount of government assistance may not be enough to support the enterprise to complete technological innovation. The delay of loan may lead to the failure of subsequent research and development, and the enterprise may even face the crisis of loss or bankruptcy. 
Government-guaranteed loan policies can address this situation. When the government reviews the relevant materials submitted by enterprises, it should conduct field investigations. After understanding and making judgment on the enterprise's operating status, credit degree, capital turnover and other basic conditions, it can choose to act as a loan guarantor as an enterprise that meets the requirements. Banks and other financial institutions are provided with guarantees to ensure that innovative enterprises can retain relevant trade secrets, expand their living space and promote the development of technological innovation.

\subsection{Tax Incentives}

Preferential tax policies can reduce the operating cost of enterprises, promote the transformation of internal business model and strategic choice of enterprises, and thus improve the technological innovation ability of enterprises. On the one hand, tax policy can reduce the cost of technology development and investment risk, and promote enterprises to increase their investment in R\&D. On the other hand, it can promote enterprises to carry out technological transformation and encourage enterprises to develop scientific and technological entrepreneurship, thus stimulating the generation and output of new technologies.

In terms of scientific and technological innovation, China will reduce the tax rate by $15 \%$ when levying corporate income tax on the key supported high-tech enterprises. At the same time, we will implement the policy of adding measurement and deduction for R\&D expenses, the policy of accelerating depreciation of fixed assets, and the policy of preferential taxation on income from technology transfer. A series of policies can help reduce the innovation cost or expenditure of enterprises, increase the capital turnover capacity of enterprises and improve the operating conditions of enterprises. In the stage of commercial marketization, the establishment of certain tax preferential policies can increase the benefits of new technology and promote the enterprises to have greater profits. Individually, the government carries out preferential tax policies for innovative talents in scientific research institutions, and gives certain rewards to relevant technical personnel after completing technological innovation and transformation achievements, including equity awards and bonuses. In addition, the national special additional deduction policy for individual income tax was introduced in 2019, which reduced the tax burden of taxpayers to a certain extent, increased the income to a certain extent, enhanced people's enthusiasm for work, and also stimulated the $R \& D$ personnel to promote technological innovation.

\subsection{Government procurement}

Government procurement means that the government purchases technological innovation transformation achievements from technological innovation enterprises. Thus, it can open up the market for innovative products, provide certain support for innovative companies, provide a relatively stable and predictable market environment, create a good start for enterprises to invest their technological innovation achievements in the market, reduce the uncertainty of technological innovation, and encourage enterprises to strengthen technological investment.

Practice has proved that the government's public procurement policy plays a great role and becomes an important means to stimulate enterprises' technological innovation policy. For example, some important government departments, such as the U.S. Department of Defense, buy high-tech products from domestic companies at above-market prices, and in large quantities. Every year, the United States sets aside $20 \%$ of the total amount of government public procurement for small and medium-sized enterprises (SMEs) for technological innovation, so as to encourage and support their technological innovation and help their development.

To sum up, in the early stage of technological innovation process, the government can support enterprises' technological innovation through certain special appropriations or some policy subsidies. In the middle stage of technological innovation process, the government improves the financial industry chain of enterprises and promotes the transformation of innovation achievements through financial guarantee, financial subsidy and achievement subsidy fund. In the later stage of the technological innovation process, the government can focus on encouraging, supporting and promoting the technological innovation results of enterprises through tax policies or government procurement. Therefore, fiscal policy is an important means to realize rational or even optimal allocation of resources, and it is of great significance to stimulate enterprises to carry out technological innovation.

\section{The problems of technological innovation under public finance in china}

With the support of national policies, the Chinese government has continuously increased its resource input in technological innovation, introduced new policies and regulations, increased financial support funds and increased government procurement expenditure. However, the current situation of technological innovation achievements has not fully presented its due effect. The reasons can be listed as follows.

\subsection{The Scale of Government Investment in Science and Technology is Insufficient}

Since the reform and opening up, China's financial investment in scientific research projects has been increasing, but there is still a large gap compared with the developed countries. Table 1 and Figure 1 show the financial investment in scientific research projects from 2009 to 2019 in China. 
Table1. Financial investment in scientific research projects from 2009 to 2019 in china

\begin{tabular}{|c|c|c|c|}
\hline & $\begin{array}{c}\text { Quantity of financial } \\
\text { investment (billion } \\
\text { yuan) }\end{array}$ & $\begin{array}{c}\text { The sequential growth rate } \\
\text { of fiscal investment }(\%)\end{array}$ & $\begin{array}{c}\text { Intensity of R\&D investment } \\
\text { (The ratio of the GDP) }\end{array}$ \\
\hline 2009 & 580.21 & 25.70 & 1.66 \\
\hline 2010 & 706.30 & 21.73 & 1.71 \\
\hline 2011 & 868.70 & 22.99 & 1.78 \\
\hline 2012 & 1029.84 & 18.55 & 2.91 \\
\hline 2013 & 1184.66 & 15.03 & 2.02 \\
\hline 2014 & 1301.56 & 9.87 & 2.06 \\
\hline 2015 & 1416.99 & 8.87 & 2.10 \\
\hline 2016 & 1567.68 & 10.63 & 2.12 \\
\hline 2017 & 1760.61 & 12.31 & 2.14 \\
\hline 2018 & 1967.79 & 11.77 & 2.24 \\
\hline 2019 & 2214.36 & 12.53 & \\
\hline
\end{tabular}

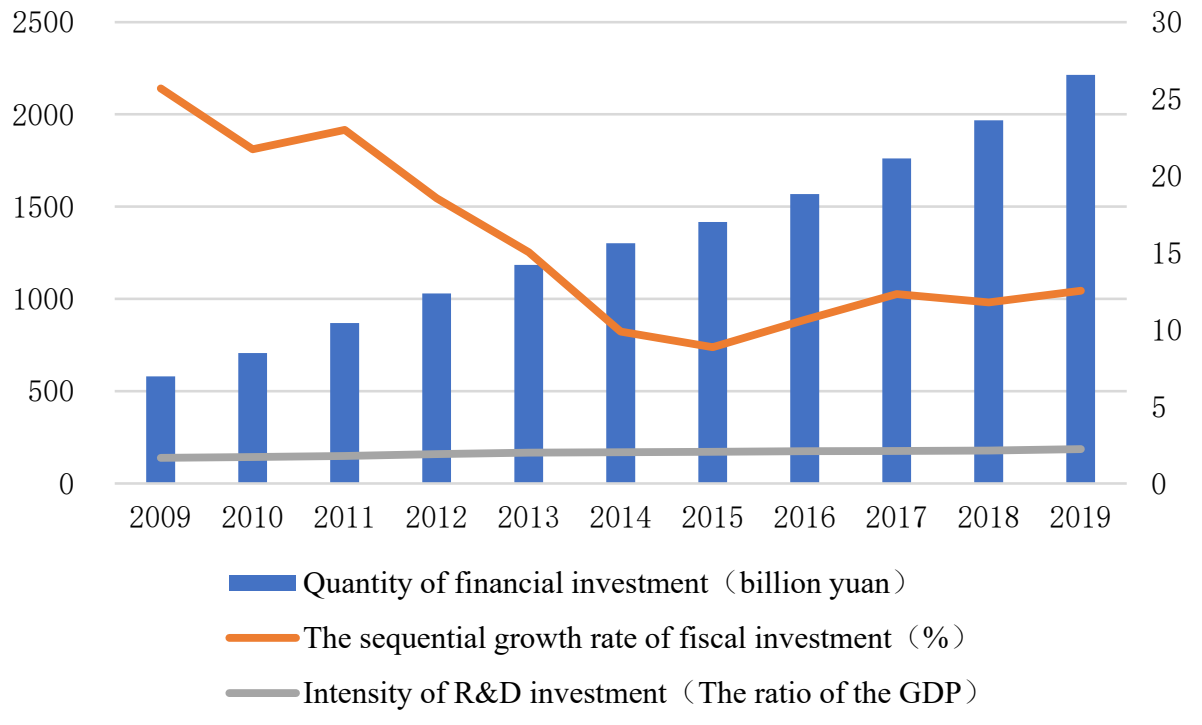

Figure 1. Financial investment in scientific research projects and R\&D investment intensity from 2009 to 2019 in china Data source: official website of National Bureau of Statistics

In 2019, the annual investment reached 2,214.36 billion yuan, an increase of $12.53 \%$ over the previous year. The R\&D investment intensity (ratio of GDP) was $2.24 \%$, but it still falls far behind the US, Japan, Germany and other innovative powers. China's spending on basic research is too low, accounting for $6.03 \%$ of its $R \& D$ spending in 2019. There is still a big gap between the proportion of basic research and the general level of more than $15 \%$ in developed countries, and the phenomenon of more R\&D output but less excellent needs to be improved urgently.

In terms of the development trajectory of various countries, the proportion of basic research funds in industrialized countries was relatively high at the early stage of industrialization. However, with the continuous improvement of science and technology, the proportion of basic research began to decline and generally remained at about $10 \%-20 \%$, basically experiencing a development trend of first high and then low. Taking China's actual conditions into consideration, we still have much room for progress.

\subsection{The Combination of Production, Learning and Research Needs To Be Explored}

For a long time, China's financial support for technological innovation basically depends on direct investment. The management system of government financial support funds in the allocation is not yet perfect. Most of the financial research funds are mainly invested in universities and government research institutions in the form of research project funds, and the capital investment in industrial research and development is relatively small. This approach of funding on the basis of research departments rather than projects raises some problems. On the one hand, duplicate funding projects and limited research scope are likely to occur; on the other hand, financial funds are likely to be deposited in a certain department or unit, hindering the effective transformation of scientific and technological achievements. As the financial funds are mainly invested in government institutions, the proportion of financial support for R\&D 
of enterprises is low. According to the investigation and analysis of the main sources of R\&D expenditure of Chinese enterprises in 2019, it can be seen that most of the R\&D expenditure of Chinese enterprises mainly comes from corporate funds, from which it can be seen that the government has insufficient support for industrial R\&D, unable to effectively guide and stimulate the R\&D investment of enterprises, and unable to effectively promote the combination of industry, education and research.

\subsection{Insufficient Tax Support for Technical Talents}

At present, there is insufficient support for technical innovation talents in terms of personal income tax reduction and exemption in China. It has set a high bar for technological rewards and not given enough tax breaks. According to the regulations, individual income tax can be reduced or exempted only when scientific and technological personnel have obtained scientific and technological awards above the provincial level, while there is no preferential policy for scientific and technological awards below the provincial level. Although such regulations can promote scientific and technological personnel to make efforts in research and development to obtain higher awards and honors to a certain extent, they are more applicable to enterprises and individuals with certain technological innovation foundation. For small and medium-sized enterprises and individuals with weak technological innovation ability, this regulation is more likely to inhibit their desire to carry out technological innovation. In addition, China currently stipulates that individual income tax should be levied on the inventions of scientific and technological personnel and the income from the transfer of technological innovation achievements, which will discourage the enthusiasm of scientific and technological personnel for technological innovation and reduce the conversion rate of technological innovation achievements. This is not conducive to promoting technological innovation and diffusion. Generally speaking, China's tax system does not pay enough attention to scientific and technological talents, and the incentive measures are not in place, which cannot effectively stimulate the innovation desire and research and development behavior of scientific and technological personnel, and thus has a negative impact on technological innovation and technology diffusion.

The Function of Government Procurement is Insufficient

Table 2 and Figure 2 reflect the scale of Chinese government procurement, the proportion of total government procurement expenditure in fiscal expenditure, and the proportion of total government procurement expenditure in GDP from 2009 to 2019.

Table2. Scale and proportion of government procurement in China

\begin{tabular}{|l|c|c|c|}
\hline & $\begin{array}{c}\text { The expenditure amount of government } \\
\text { procurement (billion yuan) }\end{array}$ & $\begin{array}{c}\text { The proportion of government procurement } \\
\text { in the total fiscal expenditure }(\%)\end{array}$ & $\begin{array}{c}\text { The proportion of government } \\
\text { procurement to GDP }\end{array}$ \\
\hline 2009 & 741.32 & 9.80 & 2.00 \\
\hline 2010 & 842.20 & 9.40 & 2.20 \\
\hline 2011 & 1130.00 & 9.20 & 2.12 \\
\hline 2012 & 1397.77 & 11.10 & 2.70 \\
\hline 2013 & 1638.11 & 11.70 & 2.90 \\
\hline 2014 & 1730.53 & 11.40 & 2.70 \\
\hline 2015 & 2107.05 & 12.00 & 3.10 \\
\hline 2016 & 3108.98 & 11.00 & 3.50 \\
\hline 2017 & 3211.43 & 12.20 & 3.90 \\
\hline 2018 & 3586.14 & 10.50 & 4.00 \\
\hline 2019 & 3306.70 & 10.00 & \\
\hline
\end{tabular}

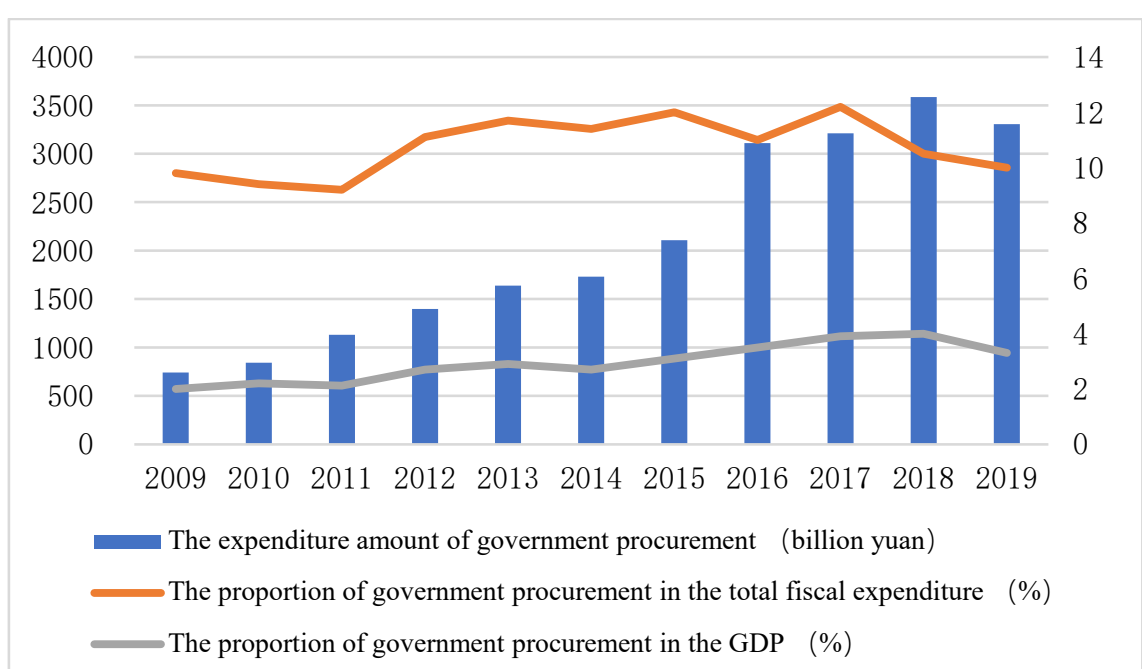

Figure 2. The proportion of government procurement expenditure in fiscal expenditure in China from 2009 to 2019 Data source: official website of National Bureau of Statistics 
In 2018, the scale of government procurement reached $3,586.14$ billion yuan, accounting for $10.5 \%$ of fiscal expenditure, and the total expenditure was $4 \%$ of GDP. In 2019, the figures are down. Many research results show that the expenditure amount of government procurement should be about $10 \%$ of GDP, and the proportion of government procurement in the total fiscal expenditure should be about $30 \%$, compared with which there is still a big gap in China. In general, the scale of government procurement in China has maintained a relatively high growth rate in terms of absolute quantity, but there is still a large space for improvement in the scale of government procurement. There are some limitations in the scope of government procurement policy's support for innovation system in China, which are mainly reflected in three aspects. First, the size of the enterprise is limited. At present, China's procurement objects mainly focus on high-tech products of enterprises with a certain scale, and it is difficult for small and medium-sized enterprises in the initial stage to get government procurement support. The second is restrictions on product procurement that focus on the end of the innovation chain. In China, government procurement supports the innovation system more by focusing on the procurement of innovative products. In terms of policy effect of stimulating innovation, it is obviously inferior to the combination of R\&D technology procurement and innovative product procurement.

\subsection{Tax Policy is Scattered}

At present, most of the tax policies are issued to solve emergencies or temporary needs, which have the advantage of strong flexibility, but also lack of systematicity due to their separate existence. At the same time, they also have the disadvantage of relatively weak guidance and not forming a complete system. In addition, many relevant policies are trial measures with low legal rank and weak authority, which increases the subjective arbitrariness and tends to have a negative impact on technological innovation. Such a tax system is generally not deep and systematic enough.

\section{The experience of developed countries}

In the process of the emergence of new technologies or the replacement of new industries, developing countries can rely on their advantages of being a lateccomer and draw lessons from the experience and lessons of some developed countries in the process of industrialization to explore their own path of economic development. The United States leads the world in technological innovation and leads the world in scientific and technological innovation. Although America's political system and national conditions are very different from China's, there are some general rules for us to learn from in terms of innovation policies. Its fiscal policies to stimulate technological innovation are as follows.

\subsection{Distribution of Enterprise Research and Development Funds}

The US government will directly provide R\&D funds, and every year there is a special fund to subsidizes technology research and development. The R\&D funds invested in the last ten years account for $50 \%$ of the total government investment. When the R\&D capacity of enterprises is insufficient, the US will increase its subsidies appropriately.

\subsection{The Fiscal Policy of "Industry-University- Research Institute" Cooperation}

In order to maximize the optimization of resource allocation, the United States fully applies technical talents to technological innovation and utilizes government subsidies and financial input to realize the organic combination of enterprises, colleges and universities and the government. The main ways include policy support, scientific and technological funding support and lowinterest loans.

\subsection{Enhancing Human Capital}

In the proportion of fiscal expenditure in the United States, in addition to the public welfare expenditure which accounts for the largest proportion, education expenditure is far ahead of other fiscal expenditure. In the United States, education funding comes from all levels of government, and since 1980, local government spending on education in the United States has reached more than $30 \%$.

\subsection{Government Procurement Employment}

The United States was one of the first countries in the world to adopt a policy of government procurement. The use of government procurement is more perfect and successful. In 1761, the United States has perfected the government procurement system and brought it into the scope of law. At present, the government adopts a unified procurement method to help enterprises' technological innovation achievements enter the market. On the one hand, government departments have a certain demand for technological innovation achievements, and the existence of such demand is conducive to the launch of innovation achievements in the market. On the other hand, the government's purchase of technological innovation products plays a role in driving the demand, which lays a good foundation for enterprises to open the market. This pull effect is particularly important during the launch phase.

\subsection{Tax Incentive Policy}

In the United States, tax credit policies mainly promote technological innovation through legislation to extend the validity of the tax credit. Moreover, in recent years, the investment and proportion of American enterprises in research and development have been increasing year by 
year, and their dominant position in the process of research and development has been constantly consolidated. This is also closely related to the government's tax incentive policy.

\subsection{Fiscal Policies to Ensure Technological Innovation of Enterprises}

The US government provides guarantees and offers discount interest subsidies to the largest enterprise innovation funds, and has set up a relatively convenient application threshold and process. In order to enable domestic enterprises to continuously enhance their R\&D level, the government provides two types of over-the-base credits. One is expense deduction, that is, the government can pay for more than $20 \%$ of the funds and technologies in the $R \& D$ process of qualified $R \& D$ institutions. The other is business reduction. The US tax law stipulates that up to $40 \%$ of the total business credit can be deducted.

\subsection{Collaborative Innovation}

In the process of technological innovation development in the United States, a variety of modes have emerged, among which the cooperative innovation, that is, the industry-university-research mode, is the representative one. The government encourages enterprise-universitygovernment cooperation, or cooperation between industries, universities and research institutes. The industry-university-research cooperation mode can not only effectively reduce the risk of technological innovation, reduce the pressure of capital turnover of enterprises, but also complement each other for different departments and institutions in terms of technology.

\section{Suggestions on technological innovation under Chinese public finance policy}

\subsection{Rational Planning of Fiscal Funds}

The construction of capital chain is of great significance to technological innovation and a perfect capital chain system is a necessary prerequisite. Under the current market economy conditions, enterprise technology innovation needs not only the investment of enterprise's own resources, but also the support from the government. Figure 3 shows total R\&D spending from 2009 to 2019, its sequential growth rate, and total R\&D spending as a share of GDP from 2009 to 2019 in China.

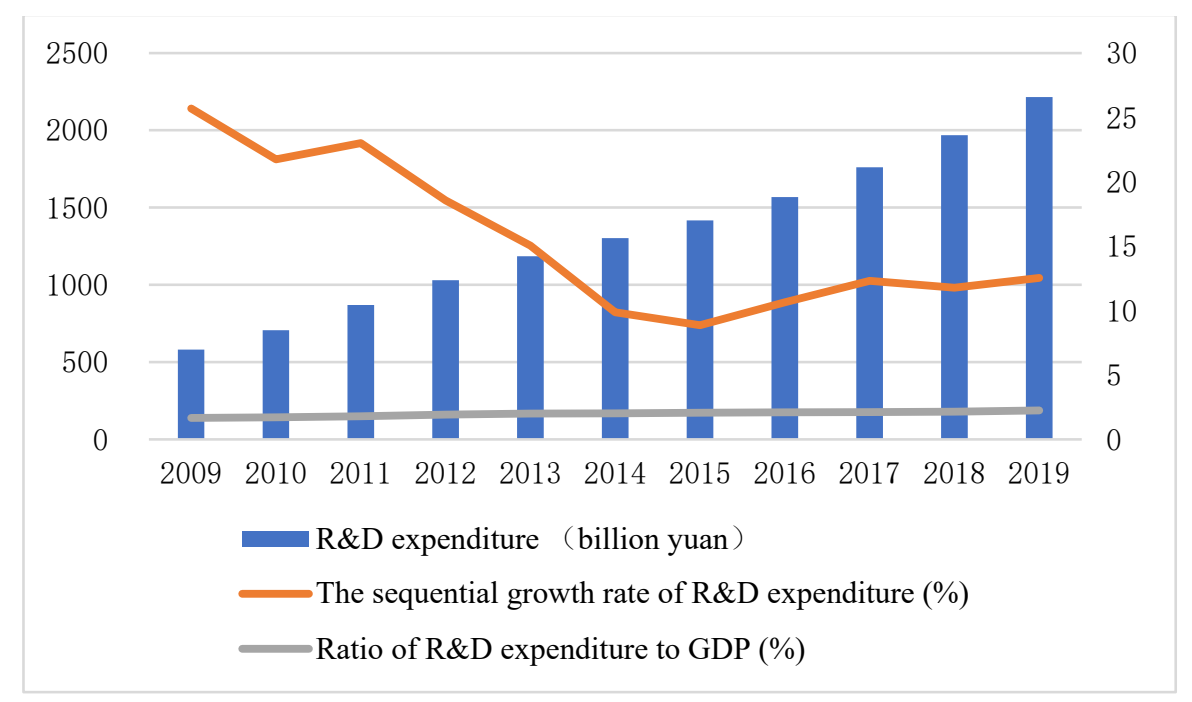

Figure 3. The proportion of China's R\&D expenditure in GDP from 2009 to 2019 Data source: official website of National Bureau of Statistics

According to data from the official website of the National Bureau of Statistics, the ratio of R\&D expenditure to GDP rose from $1.66 \%$ to $2.24 \%$ during the period of 2009-2019, which is a slight increase and a big gap with developed countries. On the basis of the existing policies, China needs to adjust the proportion of financial technology investment in GDP. We can refer to the situation of developed countries and try to control it within $20-30 \%$. Of course, this goal needs to be achieved gradually.

In addition, the government can also broaden the channels for the use of financial funds, organize relevant technical personnel for training, provide certain financial incentives according to the output scale and output benefits, and provide certain material support for enterprises that fail in technology research and development. The government should give full play to the fiscal leverage to enable enterprises to rebuild their funds.

\subsection{Strengthen Supervision Over Funds}

When providing subsidies to enterprises for technological innovation, the government should also pay attention to the management of funds, which is not only related to fairness and justice, but also related to the technology output rate. The government can establish a corresponding big data platform for capital supervision and build a government based on the rule of law. In accordance with 
the requirements of an innovative and clean government, we should make reasonable planning and design to make government procurement, budget, contract business, subsidies, preferential policies and other related fund flows transparent. Through the realization of these measures to achieve dynamic supervision, effective identification of risk mechanism, to achieve the government internal control and internal audit closed-loop management and service. At the same time, the approval process of fiscal funds should be improved, and the society, enterprises and the government should supervise the use of fiscal policy subsidies and preferential funds. Make records and report to relevant departments regularly. In addition, a targeted performance evaluation system can be formulated and improved to ensure the efficiency of implementation.

\subsection{Increase Investment in Education}

Talent is undoubtedly the most important factor in technological innovation, so increasing financial investment and cultivating high-quality talents is the fundamental to promote technological innovation. The shortage of innovative talents is still an important problem hindering technological innovation in China. Therefore, the government's financial investment in education should achieve steady growth, so that it can adapt to China's economic development and keep up with the pace of technological progress. At the same time, attention should be paid to determining the direction and structure of educational investment, which should pay attention to both basic education and higher education. In addition, the government should make rational use of the existing resources to improve the efficiency of human resources development.

The industry-university-research model needs to be vigorously promoted to encourage the cooperation among enterprises, universities and the government, so as to provide students with a good environment for innovation and cultivate their innovation ability. At the same time, certain encouragement and financial rewards are given to students' innovation output to stimulate their interest and potential in innovation, so as to cultivate excellent reserve forces for technological innovation research and development, which are fed back to enterprises and the government.

\subsection{Improve Government Procurement Policies}

Government procurement policy was originally put forward and implemented for the purpose of improving the efficiency of government expenditure. After a long period of development, it has acquired new significance and value, and has become an important way for the government to regulate the market economy. One important function is to drive technological innovation from demand through government procurement. In order to promote technological innovation, it is necessary to further improve the relevant rules and regulations, and mainly choose the technological innovation projects with good development prospects or profound influence on social development to be supported. The government should moderately incline to the enterprises in the inferior position. At the same time, the government should increase the amount of government procurement to bring it closer to the international level.

\subsection{Improve the Preferential Tax System}

The technological innovation of enterprises cannot be separated from the support of public financial policy, and tax preference is an important part of it. At present, there is still a gap between the scope of tax preference for technological innovation enterprises in China and that of developed countries such as the United States. On the basis of income tax, China can use various tax incentives to reduce tax for innovative enterprises and expand the scope of tax incentives. The government can reasonably adjust, defer or exempt the income tax for innovative enterprises that lose money due to research and development or technology development problems. Government exemptions from income tax should be extended to allow companies to pursue technological innovation without distraction. The government can also reduce or exempt the maximum amount of income tax on the salaries, allowances and subsidies obtained by researchers, and attach importance to the introduction and training of technical research and development personnel.

In addition, the government can also take advantage of the advantages of the digital economy era, combined with the construction of Digital China, improve the tax administration system, build a cloud service platform, continue to optimize the enterprise technology innovation commercialization ability, and gradually integrate with the international tax management digital platform.

\section{References}

1. Arrow,K.J.The economiac implications of learning by doing $[\mathrm{J}]$. Review of Economic Studies, 1962, 29, (2):155-173.

2. Cheng Delin.Public Finance Policy and Technology Innovation and Diffusion [J]. Science and Technology Progress and Countermeasures,2005(05):74-76.

3. Tong Dalong. Research on the Financial Policy of Encouraging Technological Innovation [J]. Special Economic Zone,2006(05):14-16.

4. Pang Deliang, Liu Jinhong. Technological Innovation and Fiscal Policy: Enlightenment from American New Economy [J]. Special Zone Economy, 2009(04):92-94.Byrne,D.M.,S.D.Oliner, and

D.E.Sichel. Is the Information Technology Revolution Over [J]? Ssrn Electronic Journal,2013, 19:59-72.

5. Jiang Gangcheng. Research on the correlation between fiscal investment and economic growth [J]. Modern Economic Information,2011(13):1.

6. Zhu Yuanyuan. Government Spending, Taxation and Independent Innovation [D]. Huazhong University of Science and Technology,2008. 
7. Wu Bin. Fiscal Policy Research on Promoting the Development of Small and Medium-sized Enterprises in China [D]. Soochow University,2012.

8. Tian Wen. Research on the Mechanism of Fiscal and Tax Policies Promoting the Improvement of Technological Innovation Performance of Enterprises [D]. Guangxi University,2016.

9. Zhang Yizuo. Tax Policy Research on Promoting Technological Innovation of Chinese Enterprises [D]. Yunnan University of Finance and Economics,2017.

10. Feng Zijin. Research on Financial Policy of Supporting Enterprise Technological Innovation in Jiangsu Province [D]. China University of Mining and Technology,2019. 